\title{
DETECÇÃO DE INCÊNDIOS FLORESTAIS POR SATÉLITES
}

Antonio Cartos Batista ${ }^{1}$

\section{INTRODUÇÃO}

Os incêndios são uma das mais importantes fontes de danos aos ecossistemas florestais nas regiões em desenvolvimento. A pressão que essas áreas florestais sofrem devido a necessidade de novas áreas destinadas às atividades agropecuárias têm aumentado consideravelmente o número de incêndios e a extensão das áreas queimadas.

Os incêndios, além dos inúmeros danos aos ecossistemas florestais, têm importância ecológica fundamental devido sua influência sobre a poluição atmosférica e mudanças climáticas, que têm impactos diretos e indiretos sobre os habitats e os ecossistemas.

A rapidez e a eficiência na detecção e monitoramento dos incêndios florestais é fundamental para a viabilização do controle do fogo, redução dos custos nas operações de combate e atenuação dos danos. Além disso, um conhecimento inadequado da localização do incêndio e extensão da área queimada prejudica a estimativa do impacto do fogo sobre o ambiente .

Portanto, os métodos de detecção e monitoramento de incêndios florestais são fundamentais para o planejamento do controle, bem como para o dimensionamento dos efeitos produzidos pelo fogo sobre o ambiente.

Diversas formas de detecção de incêndios florestais podem ser utilizadas. Dependendo das características do local, principalmente extensão da área a ser monitorada, pode se utilizar meios de detecção através de vigilância terrestre por postos de vigilância e torres de observação, patrulhamento aéreo com aeronaves e monitoramento por imagens de satélites.

Para países de grande extensão territorial, como o Brasil, o monitoramento dos incêndios florestais, a nível nacional e em escalas regionais, através de imagens de satélites é o meio mais eficiente e de baixo custo, quando comparado com os demais meios de detecção. O planejamento nacional das atividades de controle de incêndios florestais, o disciplinamento das atividades de uso do fogo controlado, bem como a avaliação dos efeitos do fogo sobre a atmosfera, só é viável através do monitoramento por satélites. Portanto, as informações obtidas devem ser de qualidade e confiáveis.

Aos estudos sobre queima de biomassa geralmente faltam informações sobre a variabilidade espaço-temporal dos incêndios florestais em escala regional e global. A aplicação de resultados locais a grandes áreas pode dar uma idéia dos padrões dos incêndios, como por exemplo: distribuições dos incêndios, quantidade de área queimada e taxa de emissão de carbono, mas os erros podem ser grandes. Observações terrestres são inadequadas para descrever a variabilidade regional, tornando-se necessária a exploração da capacidade de observação dos satélites. No entanto, medições a partir de observações terrestres são necessárias para avaliar o desempenho das técnicas dos satélites (Razafimpanilo et al, 1995).

\section{Monitoramento de focos de calor}

O lançamento em 1972 do primeiro satélite Landsat possibiltou detectar alterações nas áreas florestais através do espaço. Desde então, as imagens termais e do infravermelho médio têm sido usadas na deteç̧ão de incêndios e estudos de mapeamento, permitindo que áreas queimadas e não queimadas sejam detectadas através do contraste entre os gradientes térmicos (Remmel \& Perera, 2001).

O Instituto Nacional de Pesquisas Espaciais (INPE), através do Sistema de Monitoramento, Prevenção e Controle de Incêndios Florestais na Amazônia - PROARCO, monitora as ocorrências de incêndios para todos os estados brasileiros através de sensores espaciais.

A expressão focos de calor é utilizada para interpretar o registro de calor captado na superfície do solo por sensores espaciais. O sensor AVHRR (advanced very high resolution radiometer) capta e registra qualquer temperatura acima de $47^{\circ} \mathrm{C}$ e a interpreta como sendo um foco de calor. Apesar da

\footnotetext{
${ }^{1}$ Professor do Curso de Engenharia Florestal, Universidade Federal do Paraná, batista@floresta.ufpr.br
} 
resolução espacial ser baixa $(1,1 \mathrm{~km})$, queimadas com áreas de no mínimo $900 \mathrm{~m} 2$ podem ser detectadas (Antunes e Ribeiro, 2000).

Como parte do esforço de monitorar e minimizar o fenômeno das queimadas, o INPE vem desenvolvendo e aprimorando desde a década de 1980 este sistema operacional de detecção de queimadas. A partir de 1998 o trabalho passou a ser feito conjuntamente com o IBAMA/PROARCO, dando ênfase particular à Amazônia. Os dados são obtidos nas imagens termais dos satélites meteorológicos NOAA quatro vezes ao dia, GOES oito vezes ao dia, e Terra e Aqua duas vezes por dia, e em seguida integrados a dois sistema geográficos de informações (SpringWeb-Queimadas e TerraLib-Queimadas) que podem ser utilizados pela Internet. As informações são disponibilizadas operacionalmente aos usuários cerca de 20 minutos após as passagens dos satélites. Todo o País e grande parte da América do Sul são cobertos pelas imagens, pois utiliza-se recepções das estações do INPE em Cachoeira Paulista, SP e de Cuiabá, MT (CPTEC/INPE, 2004).

Apesar disso, o monitoramento dos incêndios florestais no Brasil ainda é deficitário, devido às limitações técnicas inerentes ao sistema utilizado e também devido a falta de estudos básicos sobre o comportamento do fogo e as características ambientais associadas à ignição e propagação dos incêndios nos diversos ecossistemas brasileiros. De acordo com Razafimpanilo et al (1995), a eficiência do monitoramento de incêndios por satélites depende de informações prévias do ambiente, tais como: características do material combustível, informações sobre regeneração natural e fenologia da vegetação, condições climáticas, etc.

\section{Parâmetros para o aperfeiçoamento do sistema atual de deteç̧ão de incêndios}

Em um estudo sobre a viabilidade de se utilizar a deteç̧ão de incêndios através de sensoriamento remoto para avaliar a alterações na cobertura florestal, Eva \& Fritz (2003) citam diversos pesquisadores que têm observado problemas com a detecção ao se usar dados sobre incêndios florestais a partir de sensoriamento remoto de baixa resolução.

De acordo com Ugarte et al (2003), a variabilidade espacial e temporal da temperatura e da reflectância do ambiente são importantes problemas a serem considerados nos algoritmos de detecção de incêndios por meio de imagens de satélites.

Diversos pesquisadores têm analisado e apresentado metodologias para aumentar a confiabilidade da detecção de incêndios através de imagens de satélite. O ponto de partida para estes estudos são as informações detalhadas obtidas dos registros de ocorrências de incêndios. Dados sobre os incêndios ocorridos em determinada região, tais como: localização, extensão da área afetada, tipo de vegetação atingida, informações sobre o comportamento do fogo (intensidade, velocidade de propagação, material combustível consumido, etc.), são fundamentais para a comparação com as imagens obtidas dos satélites nestes mesmos horários e locais. O primeiro passo para avaliação da eficiência do sistema de monitoramento de incêndios, através de sensoriamento remoto é a disponibilidade de registros sobre a ocorrência de incêndios, a fim de se poder comparar os focos de calor detectados pelos satélites com os incêndios realmente ocorridos. Esse tem sido um grande obstáculo para a avaliação da qualidade do sistema de detecção de incêndios florestais por satélites, já que não existe no Brasil um sistema padronizado de registro de ocorrência de incêndios florestais. Os dados sobre ocorrências de incêndios são obtidos por diferentes organizações, governamentais ou não, variando as qualidades das informações sobre os incêndios em função da qualificação da pessoa e/ou da organização responsável pela coleta dos dados. Isso dificulta muito a interpretação das informações sobre as ocorrências de incêndios para o estabelecimento de um perfil definido dos incêndios florestais nas diversas regiões do Brasil.

O Laboratório de Incêndios Florestais da UFPR vem desenvolvendo estudos com o objetivo de levantar informações básicas que possam aprimorar o sistema de monitoramento e detecção de incêndios florestais do Estado do Paraná. O Projeto "Zoneamento de Risco de Incêndios Florestais para o Estado do Paraná", financiado pela Fundação Araucária é um exemplo disso. Analisando características de uso e ocupação do solo, condições climáticas, cobertura vegetal e registros de ocorrência de incêndios de um período de 10 anos (1992-2001), foi possível elaborar um mapeamento do risco de incêndios florestais do Paraná. Foram analisados registros de 15000 incêndios no território paranaense nesse período (Batista, Oliveira e Soares, 2002). Comparando-se parte destes dados (1999 
- 2002) com os focos de calor observados através do sistema de monitoramento de incêndios do INPE, verificou-se uma discrepância muito grande tanto no número observado como na localização dos incêndios. O número de incêndios realmente detectados variou muito de uma região para outra, sendo que a média de acertos não ultrapassou $30 \%$, no período analisado. Resultados mais detalhados estão sendo objeto de um trabalho de dissertação de mestrado em Engenharia Florestal na UFPR. Remmel \& Perera (2001) obtiveram resultados semelhantes quando compararam ocorrências de incêndios e focos detectados por satélites no norte do Canadá. Observaram que os incêndios corretamente detectados variaram entre $1 / 3$ e $2 / 3$ do total de incêndios realmente observados. No entanto, observaram que a detecção é mais precisa quanto maior a extensão da área queimada. Martin \& Chuvieco $^{2}$ (1995), citados por Remmel \& Perera (2001) também observaram a existência de vários incêndios de grande extensão detectados com grande precisão, enquanto incêndios de pequena extensão foram detectados com baixa precisão.

As condições meteorológicas são outro grupo de variáveis muito importante quando se trabalha com monitoramento ambiental por satélites A qualidade das imagens de satélites e sua interpretação dependem basicamente das condições meteorológicas. Uma das principais limitações do uso de imagens de satélites na detecção de incêndios florestais é a presença de nuvens.

A frequência e distribuição dos incêndios florestais também está fortemente associada às condições meteorológicas. Através do monitoramento das condições meteorológicas é possível se fazer previsão do risco de incêndios, mediante o cálculo de índices de risco, definindo-se para um determinado período as áreas de maior probabilidade de ocorrer incêndios.

A análise conjunta de variáveis meteorológicas, ou índices de risco de incêndios, e focos de calor possibilita uma melhor definição dos incêndios florestais de uma determinada região, reduzindo o número de falsos alarmes. O Instituto SIMEPAR, orgão do governo estadual responsável pela rede meteorológica do Paraná, está iniciando um trabalho de monitoramento de incêndios florestais, associando as informações dos focos de calor do INPE com os dados meteorológicos. Porém, é imprescindível que se disponha de uma rede meteorológica bem distribuida e estruturada, como é o caso do Paraná. Nos outros estados brasileiros, há uma boa rede de estações meteorológicas nas regiões sul, sudeste e nordeste. Nas regiões norte e centro-oeste, o número de estações ainda não é suficiente para cobrir toda a área. No entanto, são nessas regiões que se observa o maior número de focos de calor, que na falta de informações adicionais, são utilizados como únicos indicadores das ocorrências de incêndios florestais. E isto, como já mencionado anteriormente, acarreta problemas significativos no planejamento do controle de incêndios e no dimensionamento dos efeitos produzidos.

As características da cobertura vegetal também são fatores condicionantes da qualidade e confiabilidade da deteç̧ão de incêndios florestais por satélites. Por exemplo: geralmente, em alguns ecossistemas, como as savanas tropicais, um incêndio começa e termina em poucas horas, e portanto, pode ser que inicie e termine entre dois intervalos consecutivos de tempo da passagem do satélite, e como consequência, o incêndio não será detectado. Por isso, várias pesquisas tem se voltado para estimativas de extensão da área queimada, cujo tempo de residência do sinal detectado pelo satélite é mais longo do que o incêndio. No entanto, a deteç̧ão da área queimada é mais difícil porque a assinatura espectral das áreas queimadas depende do tipo de cobertura vegetal e da suas condições (Barbosa, Gregoire e Pereira ${ }^{3}$, 1999, citados por Boschetti et al, 2003).

Os combustíveis florestais, que são produto da cobertura vegetal e sua dinâmica, são importantes parâmetros nos processos de ignição e propagação dos incêndios. O conhecimento das características básicas dos combustíveis, tais como: tipo, quantidade, continuidade e arranjo, são muito úteis, tanto na estimativa do risco como na previsão do comportamento dos incêndios (Castro et al, 2003, Green et al. 1995, Chuvieco e Congalton, 1989, Gouma e Chronopoulou-Sereli, 1998). Portanto, a caracterização dos combustíveis florestais (modelagem) e a sua associação com os focos de calor pode aumentar a eficiência na detecção dos incêndios florestais. Trabalhos sobre modelagem dos combustíveis florestais no Brasil estão sendo desenvolvidos para as áreas de reflorestamento de pinus

\footnotetext{
${ }^{2}$ Martin, M. P.; Chuvieco, E. 1995. Mapping end evaluation of burned land from multitemporal analysis of AVHRR NDVI images. EARSeL Adv. Remote Sens. 4, 7-13.

${ }^{3}$ Barbosa, P. M.Gregoire, J. M.; Pereira, J. M. C. 1999. An algorithm for extracting burned areas from time series of AVHRR GAC data applied at a continental scale. Remote Sens. Environ., 69, 253-263.
} 
e eucaliptos na região sul (Soares et al., 2002) e para o cerrado na região central do Brasil ( Ottmar et al., 2001).

\section{Considerações gerais}

A extensão territorial do Brasil e a diversidade de sua cobertura vegetal, bem como o número expressivo de ocorrências de incêndios florestais verificados no país, são fatores que enfatizam a necessidade de um sistema cada vez mais aprimorado e consistente de detecção de incêndios florestais para facilitar as atividades de planejamento de prevenção, controle e mitigação dos danos.

A detecção de incêndios através do sensoriamento remoto é a forma mais viável para o Brasil, devido a magnitude e a diversidade das características dos ecossistemas florestais. No entanto, há necessidade de aperfeiçoar esse sistema, utilizando a análise de vários outros parâmetros, que associados aos focos de calor obtidos das imagens de satélites, propiciem um aumento da precisão na detecção de focos de incêndios e áreas queimadas. Também é necessário que sejam intensificadas as pesquisas visando desenvolver algoritmos e modelos que possibilitem um melhor desempenho na detecção de incêndios através de imagens de satélites.

O aperfeiçoamento do sistema de detecção de incêndios depende de informações atualizadas dos registros oficiais de ocorrências de incêndios florestais. Por isso, há necessidade de se estabelecer uma parceria entre as entidades públicas e privadas de controle de incêndios florestais, visando estabelecer um cadastro nacional sobre as ocorrências de incêndios no Brasil, com informações padronizadas que possibilitem traçar um perfil bem delineado dos incêndios florestais nas várias regiões do país.

A ampliação da rede meteorológica nacional para o monitoramento e a previsão mais detalhada das condições meteorológicas e o cálculo de índices de risco de incêndios florestais é outra alternativa que deve ser perseguida para ampliar as variáveis empregadas juntamente com o sensoriamento remoto na detecção de incêndios.

As pesquisas sobre as características dos combustíveis florestais nos ecossistemas vegetais brasileiros são muito importantes no desenvolvimento de metodologias mais apuradas para a indicação do nível de risco de incêndios e o monitoramento e detecção de incêndios florestais.

\section{REFERÊNCIAS}

ANTUNES, M. A. H. 2000. Uso de satélites para detecção de queimadas e para avaliação do risco de fogo. Ação Ambiental, 12:24-27.

BATISTA, A. C.; OLIVEIRA, D. S.; SOARES, R. V. 2002. Zoneamento de risco de incêndios florestais para o Estado do Paraná. Curitiba, FUPEF do Paraná, Série Técnica vol.2 n. 2, 86p.

BOSCHETTI, L.; BRIVIO, P. A.; GREGOIRE, J. M. 2003. The use of Meteosat and GMS to detect burned areas in tropical environments. Remote Sensing of Environment, 85:78-91.

CASTRO, F. X.; TUDELA, A.; SEBASTIÀ, M. T. 2003. Modeling moisture content in shrubs to predict fire risk in Catalonia (Spain). Agricultural and Forest Meteorology, 116:49-59.

CHUVIECO, E.; CONGALTON, R. G. 1989. Aplication of remote sensing and geographic information systems to forest fire hazard mapping. Remote Sens. Environ., 29:147-159.

CPTEC/INPE - CENTRO DE PREVISÃO DO TEMPO E ESTUDOS CLIMÁTICOS/ INSTITUTO NACIONAL DE PESQUISAS ESPACIAIS. 2004. Apresentação da página "Queimadas". Disponível em: http://www.cptec.inpe.br/queimadas/

EVA, H.; FRITZ, S. 2003. Examining the potential of using remotely sensed fire data to predict areas of rapid forest change in South America. Applied Geography, 23: 189-204.

GOUMA, V.; CHRONOPOULOU-SERELI, A. 1998. Wildland fire danger zoning - A methodology. Int. J. Wildland Fire, 8(1):37-43.

GREEN, K.; FINNEY, M. CAMPBELL, J.; WEISTEIN, D.; LANDRUM, V. 1995. Using GIS to predict fire behavior. J. Forestry, 93:21-25. 
OTTMAR, R. D.; VIHNANEK, R. E.; MIRANDA, H. S.; SATO, M. N.; ANDRADE, S. M. A. 2001. Stereophoto series for quantifying Cerrado fuels in Central Brazil, v 1. USDA F.S. Gen. Tech. Report, PNW-GTR-519, 87p.

RAZAFIMPANILO, H.; FROUIN, R.; IACOBELliS, S. F.; SOMERVILlE, R. C. J. 1995. Methodology for estimating burned area from AVHRR reflectance data. Remote Sens. Environ. 54:273-289.

REMMEL, T. K.; PERERA, A. H. 2001. Fire mapping in a northern boreal forest: assessing AVHRR/NDVI methods of change detection. Forest Ecology and Management 152:119-129.

SOARES, R. V.; BATISTA, A. C.; SOUZA, L. J. B. 2002. Fuel load in Eucalyptus dunnii and Pinus taeda plantations in southern Brazil. In: Viegas, D. X.(ed.) Forest Fire Research \& Fire Safety.

UGARTE, M. F.; ZEQUEIRA, R. I.; LÓPEZ, F. 2001. An approach for the compensation of the background variability in fire detection systems. Infrared Physics \& Technology, 42:23-30. 